\title{
The crossflow piezo-electrooptic effect in crystals. Example of lithium tantalate
}

\begin{abstract}
A.S.Andrushchak, I.V.Sydoryk, M.V.Kaidan, R.O.Vlokh
Institute of Physical Optics, 23 Dragomanov Str., 79005 Lviv, Ukraine

Received February 16, 2000, in final form September 26, 2000

In the present paper the thermodynamic and phenomenological descriptions of the crossflow piezo-electrooptic effect in crystals have been made. For example the necessary experimental measurements of this effect have been carried out in the lithium tantalate crystals. For these crystals at first the $P_{33113}-P_{11113}=-4.6 \cdot 10^{-19} \mathrm{~m}^{3} / \mathrm{N} \cdot \mathrm{V}$ absolute coefficients difference of crossflow piezo-electrooptic effect were determined by two measurement methods.
\end{abstract}

Key words: thermodynamic and phenomenological descriptions, crossflow piezo-electrooptic effect, lithium tantalate crystals, induced birefringence

PACS: $77.84 . \mathrm{Dc}, 78.20 . \mathrm{Hp}, 78.20 . \mathrm{Fm}$

\section{Introduction}

The crossflow piezo-electrooptic effect, resulting from mutual interaction of piezoand electrooptic effects in crystal materials, is poorly investigated because of its small values [1] on the background of a direct action of the piezo- or electrooptic effects.

The aim of the present work is to carry out thermodynamic and phenomenological description of the crossflow piezo-electrooptic effect and make necessary experimental measurements for its verification.

\section{Thermodynamic description}

According to the general thermodynamic theory [2-4], a crystal appears as a thermodynamic system the monocrystal state of which is determined by certain numbers of variables. Mechanical stress $\sigma_{i j}$, electrical field strength $E_{i}$ and temperature $\mathrm{T}$ are chosen as independent variables. Herein Gibbs free energy $\mathrm{G}$ is assumed as thermodynamic function for which $[1,5]$ :

$$
G=U-\boldsymbol{\varepsilon} \boldsymbol{\sigma}-\boldsymbol{E}(\boldsymbol{D} / 4 \pi)-T S,
$$


where $\mathrm{U}$ is the inner energy. Then, the components of the mechanical deformation $\varepsilon_{i j}$, electrical field induction $D_{i}$ and entropy $\mathrm{S}$ will be functions of independent variables. Let's spread in the MacLaurin's series the $\varepsilon_{i j}$ and $D_{i}$ up to the third order of smallness (no thermal effects are taken into account) because their meanings of the second and the third order of smallness are insignificant [6]). Setting for convenience $\delta_{m}=D_{m} / 4 \pi$, we will have:

$$
\begin{aligned}
\varepsilon_{k l}= & \frac{\partial \varepsilon_{k l}}{\partial \sigma_{i j}} \sigma_{i j}+\frac{\partial \varepsilon_{k l}}{\partial E_{n}} E_{n}+\frac{1}{2}\left[\frac{\partial^{2} \varepsilon_{k l}}{\partial \sigma_{i j} \partial \sigma_{q r}} \sigma_{i j} \sigma_{q r}+2 \frac{\partial^{2} \varepsilon_{k l}}{\partial \sigma_{i j} \partial E_{n}} \sigma_{i j} E_{n}+\frac{\partial^{2} \varepsilon_{k l}}{\partial E_{n} \partial E_{o}} E_{n} E_{o}\right] \\
+ & \frac{1}{6}\left[\frac{\partial^{3} \varepsilon_{k l}}{\partial \sigma_{i j} \partial \sigma_{q r} \partial \sigma_{s t}} \sigma_{i j} \sigma_{q r} \sigma_{s t}+3 \frac{\partial^{3} \varepsilon_{k l}}{\partial \sigma_{i j} \partial \sigma_{q r} \partial E_{n}} \sigma_{i j} \sigma_{q r} E_{n}\right. \\
& \left.+3 \frac{\partial^{3} \varepsilon_{k l}}{\partial \sigma_{i j} \partial E_{n} \partial E_{o}} \sigma_{i j} E_{n} E_{o}+\frac{\partial^{3} \varepsilon_{k l}}{\partial E_{n} \partial E_{o} \partial E_{p}} E_{n} E_{o} E_{p}\right] \\
\delta_{m}= & \frac{\partial \delta_{m}}{\partial \sigma_{i j}} \sigma_{i j}+\frac{\partial \delta_{m}}{\partial E_{n}} E_{n}+\frac{1}{2}\left[\frac{\partial^{2} \delta_{m}}{\partial \sigma_{i j} \partial \sigma_{q r}} \sigma_{i j} \sigma_{q r}+2 \frac{\partial^{2} \delta_{m}}{\partial \sigma_{i j} \partial E_{n}} \sigma_{i j} E_{n}+\frac{\partial^{2} \delta_{m}}{\partial E_{n} \partial E_{o}} E_{n} E_{o}\right] \\
+ & \frac{1}{6}\left[\frac{\partial^{3} \delta_{m}}{\partial \sigma_{i j} \partial \sigma_{q r} \partial \sigma_{s t}} \sigma_{i j} \sigma_{q r} \sigma_{s t}+3 \frac{\partial^{3} \delta_{m}}{\partial \sigma_{i j} \partial \sigma_{q r} \partial E_{n}} \sigma_{i j} \sigma_{q r} E_{n}\right. \\
& \left.+3 \frac{\partial^{3} \delta_{m}}{\partial \sigma_{i j} \partial E_{n} \partial E_{o}} \sigma_{i j} E_{n} E_{o}+\frac{\partial^{3} \delta_{m}}{\partial E_{n} \partial E_{o} \partial E_{p}} E_{n} E_{o} E_{p}\right]
\end{aligned}
$$

Besides, the following equations are valid [5]:

$$
\frac{\partial G}{\partial \sigma_{k l}}=-\varepsilon_{k l}, \quad \frac{\partial G}{\partial E_{m}}=-\delta_{m}, \quad \frac{\partial \delta_{m}}{\partial \sigma_{k l}}=\frac{\partial \varepsilon_{k l}}{\partial E_{m}} .
$$

Considerations of the physical sense of the partial derivatives are given more in full in [1]. We will take into consideration only components describing crossflow effects. They are:

$$
A_{k l i j n}=\frac{\partial^{2} \varepsilon_{k l}}{\partial \sigma_{i j} \partial E_{n}}=-\frac{\partial^{3} G}{\partial \sigma_{i j} \partial \sigma_{k l} \partial E_{n}}=\frac{\partial S_{k l i j}}{\partial E_{n}} \equiv \frac{\partial^{2} \delta_{n}}{\partial \sigma_{i j} \partial \sigma_{k l}}=\frac{\partial d_{n i j}}{\partial \sigma_{k l}} .
$$

It is a correction part to the elastic compliance constant $S_{k l i j}$, which is connected with the electrical field $E_{n}$ acting in the crystal, or the same, correction part to the reverse piezoelectric effect constant $d_{n i j}$ under the action of the mechanical stress $\sigma_{i j}$. It is fifth-rank tensor, which describes a crossflow piezo-electrostrictive effect caused in the crystal by mutual interaction of the electrical field and the mechanical stress. Furthermore:

$$
\begin{aligned}
B_{\text {mnijo }} & =\frac{\partial^{3} \delta_{m}}{\partial \sigma_{i j} \partial E_{n} \partial E_{o}}=-\frac{\partial^{4} G}{\partial \sigma_{i j} \partial E_{m} \partial E_{n} \partial E_{o}}=\frac{\partial \mu_{m n i j}}{\partial E_{o}} \equiv \frac{\partial}{\partial E_{o}}\left(\frac{\partial k_{m n}}{\partial \sigma_{i j}}\right) \\
& =\frac{\partial}{\partial \sigma_{i j}}\left(\frac{\partial k_{m n}}{\partial E_{o}}\right)=\frac{\partial \rho_{m n o}}{\partial \sigma_{i j}} .
\end{aligned}
$$


Here $k_{m n}$ - permittivity tensor and $B_{m n i j o}$ - a tensor of crossflow piezo-electrooptic effect, which determine the change of the piezooptic module $\mu_{m n i j}=\partial k_{m n} / \partial \sigma_{i j}$ under the action of the electrical field $E_{o}$, or the same, the change of the liner electrooptic effect tensor $\rho_{m n o}=\partial k_{m n} / \partial E_{o}$ under the action of the mechanical stress $\sigma_{i j}$.

Then, as parts of the second order of smallness are neglected, the simplified correlations (2) and (3) are:

$$
\begin{aligned}
\varepsilon_{k l} & =S_{k l i j} \sigma_{i j}+d_{n k l} E_{n}+A_{k l i j n} \sigma_{i j} E_{n}, \\
D_{m} & =4 \pi d_{m i j} \sigma_{i j}+E_{n}\left[k_{m n}+\mu_{m n i j} \sigma_{i j}+\rho_{m n o} E_{o} / 2+B_{m n i j o} \sigma_{i j} E_{o} / 2\right],
\end{aligned}
$$

where $d_{m i j}$ is a tensor of piezoelectric effect.

\section{Phenomenological description}

In the given work, the phenomenological description of a crossflow effect needed for the explanation of our experimental measurements is carried out.

As is generally known, the external action (be it the mechanical stress $\sigma_{m n}$ or the external electric field $E_{l}$ ) exerted on the crystal sample results in the change of birefringence $\delta\left(\Delta n_{k}\right)=\delta n_{i}-\delta n_{j}$ (or refractive indices $\delta n_{i}, \delta n_{j}$ ) of the sample as well as its length $\delta t_{k}$ in the direction $\mathrm{k}$ of light propagation, which are registered by polarization-optic method through the change of an optical path difference $\delta \Delta_{k}$ of this sample:

$$
\delta \Delta_{k}=\delta\left(\Delta n_{k} t_{k}\right)=t_{k} \delta\left(\Delta n_{k}\right)+\Delta n_{k} \delta t_{k} .
$$

The value $\delta\left(\Delta n_{k}\right)$ or $\delta n_{i}, \delta n_{j}$ can be determined from the tensor for polarization constants $a_{i j}$. Beside the coefficients of piezo- $\pi_{i j m n}$ and linear electrooptic $r_{i j l}$ effects, this tensor in the first approximation for acentric crystals also contains the coefficients of their crossflow effect [1], analogous to (8):

$$
\Delta a_{i j}=\pi_{i j m n} \sigma_{m n}+r_{i j l} E_{l}+P_{i j m n l}\left(\sigma_{m n} E_{l}\right),
$$

where $P_{i j m n l}=\partial \pi_{i j m n} / \partial E_{l}=\partial r_{i j l} / \partial \sigma_{m n}$ is the tensor of crossflow piezo-electrooptic effect (tensor of absolute coefficients), $\sigma_{m n} E_{l}=g_{m n l}$ is the 3-rank tensor, which equals the product of the 2-rank tensor $\sigma_{m n}$ and vector $E_{l}$. From a thermodynamic description of crossflow piezo-electrooptic effect $P_{m n i j l}$ (see formula (6)), one can describe symmetrical properties of this tensor while replacing the indexes $P_{i j m n l}=$ $P_{j i m n l}=P_{i j n m l}=P_{i j l m n}$. The complete form of this tensor is given in [7].

Analogously, the value $\delta t_{k}$ is determined from the deformation tensor $\varepsilon_{k l}$ (see formula (7)), which beside the coefficients of elastic $S_{k l i j}$ and piezoelectric $d_{n k l}$ effects also contains the coefficients of their crossflow $A_{k l i j n}$ effect. This crossflow $A_{k l i j n}$ effect is named "false" effect in our case.

To derive the necessary operating correlations we use the matrix interpretation of the processed tensors. For a crystal with small initial birefringence the correlation (9) will be simplified to $\delta \Delta_{k}=t_{k} \delta\left(\Delta n_{k}\right)$, where the $\delta\left(\Delta n_{k}\right)$ value is equal to [5,8]: 


$$
\delta\left(\Delta n_{k}\right)=-\pi_{k m}^{*} \sigma_{m} / 2
$$

Here $\pi_{k m}^{*}=\pi_{i m} n_{i}^{3}-\pi_{j m} n_{j}^{3}$ is a known piezooptic coefficient of the induced birefringence. For half-wave stresses $\sigma_{m}^{o}$, when $\delta \Delta_{k}=\lambda / 2$ ( $\lambda$ is a length of light wave), one can obtain:

$$
\lambda / 2=-\pi_{k m}^{*} \sigma_{m}^{o} t_{k} / 2 .
$$

After applying the electric field $E_{l}$, for repeatedly measured half-wave stresses $\sigma_{m}^{o^{\prime}}$, we obtain:

$$
\lambda / 2=-\pi_{k m}^{*} \sigma_{m}^{o^{\prime}} t_{k} / 2-P_{k m l}^{*} \sigma_{m}^{o^{\prime}} E_{l} t_{k} / 2 .
$$

Analogously $P_{k m l}^{*}=P_{i m l} n_{i}^{3}-P_{j m l} n_{j}^{3}$ is the crossflow piezo-electrooptic coefficient of the induced birefringence. Mutual solution of (12) and (13) gives us the value of this coefficient to be searched for:

$$
P_{k m l}^{*}=\lambda\left[\left(\sigma_{m}^{o^{\prime}} / \sigma_{m}^{o}\right)-1\right] /\left(\sigma_{m}^{o^{\prime}} E_{l} t_{k}\right) .
$$

A similar formula can be obtained at measuring the magnitudes of half-wave electric fields $E_{l}^{o}$ and $E_{l}^{o^{\prime}}$ for $\sigma_{m}=0$ and $\sigma_{m} \neq 0$ accordingly.

\section{Experimental results}

The measurements of crossflow piezoelectrooptic effect were carried out using the polarisation-interferometrical technique by Senarmont method and half-wave stresses method [5].

To exclude a possible error, connected with the measurement of "false" crossflow effect, the $\mathrm{LiTaO}_{3}$ crystals with a small initial birefringence $\left(\Delta n_{k}=0,005\right)$ were used. For these crystals, the elastic component in (9) and therefore "false" crossflow effect could be neglected.

We have determined the crossflow piezo-electrooptic effect $P_{22113}^{*}$ component on the sample of direct cut, when $k \| Y$, $\sigma_{m} \| X$ and $E_{l} \| Z$. In the figures the dependences for the $\delta\left(\Delta n_{2}\right)$ value under the

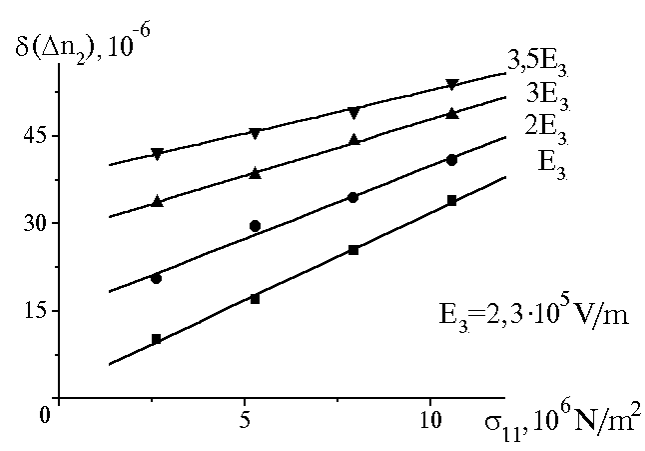

Figure 1. The dependences of birefringence change $\delta\left(\Delta n_{2}\right)$ for lithium tantalate crystals on the normal mechanical stress $\sigma_{11}$ for different magnitudes of electrical fields $E_{3}$ (for light wave $\lambda=0,6328 \mu \mathrm{m}$ and temperature $\mathrm{T}=293 \mathrm{~K})$.

normal mechanical stress $\sigma_{11}$ for different magnitudes of $E_{3}$ (figure 1) are shown as well as the $\delta\left(\Delta n_{2}\right)$ value under the electrical field $E_{3}$ for different magnitudes of $\sigma_{11}$ (figure 2). From the changes of angular coefficients for linear interpolation of these behaviours we have calculated the average magnitudes of $P_{22113}^{*}=-5.0 \cdot 10^{-18} \mathrm{~m}^{3} / \mathrm{N}$ - V (from figure 1) and $P_{22113}^{*}=-4.4 \cdot 10^{-18} \mathrm{~m}^{3} / \mathrm{N} \cdot \mathrm{V}$ (from figure 2). 


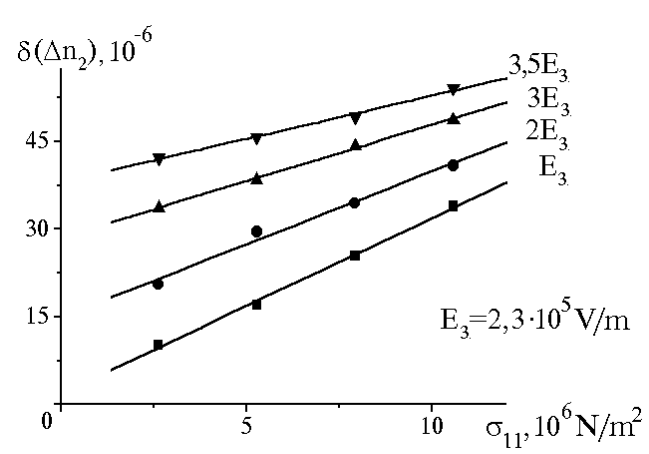

Figure 2. Analogous to figure 1 the dependences of $\delta\left(\Delta n_{2}\right)$ on the electrical fields $E_{3}$ for different magnitudes of mechanical stress $\sigma_{11}$.

The difference of these coefficients can be explained by the induced rotation of the optical indicatrix around the $\mathrm{X}$ axis under the action of the mechanical stress $\sigma_{11}$. It leads to the change of extraordinary index $n_{e}$ of light wave according to the known equation:

$$
\delta n_{e}=n_{e}\left(1-\cos \left(\pi_{41} \sigma_{11} /\left(n_{e}^{-2}-n_{o}^{-2}\right)\right) .\right.
$$

Taking this into account, we have found the new magnitude of $P_{22113}^{*}=-4.7 \cdot 10^{-18}$ $\mathrm{m}^{3} / \mathrm{N} \cdot \mathrm{V}$ from figure 1 .

This coefficient $P_{22113}^{*}$ has also been determined from the method of half-wave stresses. Having determined the half-wave mechanical stress $\sigma_{m}^{o}$ for $E_{l}=0$ and $\sigma_{m}^{o^{\prime}}$ upon the action of electrical field $E_{l} \neq 0$, we have calculated the magnitude $P_{k k m m l}^{*}$ according to formula (14), which was equal $P_{22113}^{*}=-5.1 \cdot 10^{-18} \mathrm{~m}^{3} / \mathrm{N} \cdot \mathrm{V}$.

It is also noted that from $P_{22113}^{*}$ one can calculate the absolute coefficients combination of crossflow piezo-electrooptic effect (taking into account that $n_{o} \approx n_{e}=$ 2.175): $P_{33113}-P_{11113} \approx P_{22113}^{*} / n_{o}^{3}=-4.6 \cdot 10^{-19} \mathrm{~m}^{3} / \mathrm{N} \cdot \mathrm{V}$.

Besides, according to (6): $P_{22113}^{*}=\partial \pi_{2211}^{*} / \partial E_{3} \approx \Delta \pi_{2211}^{*} / \Delta E_{3}$, and therefore at the electrical field change of $\Delta E_{3}=2.3 \cdot 10^{5} \mathrm{~V} / \mathrm{m}$ the change of piezooptic coefficient is equal $\Delta \pi_{2211}^{*}=P_{22113}^{*} \Delta E_{3}=1.1 \cdot 10^{-12} \mathrm{~m}^{2} / \mathrm{N}$. For comparison, the magnitude of coefficient $\pi_{2211}^{*}$ from our measurements is equal to $10.4 \cdot 10^{-12} \mathrm{~m}^{2} / \mathrm{N}$.

\section{Conclusions}

1. The thermodynamic descriptions of crossflow piezo-electrooptic effect in crystals and the necessary phenomenological descriptions for anisotropic materials with small initial birefringence have been made in the paper.

2. For lithium tantalate crystals, at first the $P_{33113}-P_{11113}=-4.6 \cdot 10^{-19} \mathrm{~m}^{3} / \mathrm{N} \cdot \mathrm{V}$ absolute coefficients difference of crossflow piezo-electrooptic effect were determined. For these crystals, the change of $\Delta \pi_{2211}^{*}$ because of crossflow effect corresponds to $\sim 10 \%$ of coefficient $\pi_{2211}^{*}$ at electrical field change of $\Delta E_{3}=2.3 \cdot 10^{5} \mathrm{~V} / \mathrm{m}$.

3. The equality (within the limits of experimental error) of the $P_{22113}^{*}$ coefficient, obtained from different measurement methods, demonstrated the correctness of our results and showed the possibility of measuring the crossflow piezo-electrooptic effect in anisotropic crystals with small initial birefringence using these methods.

\section{References}

1. Sirotin Yu.I., Shaskolskya M.P. Essentials of Crystallophysics. Moscow, Nauka, 1979 (in Russian). 
2. Mason W. Crystal Physics of Interaction Processes. New-York, Lond. Acad. Press, 1966.

3. Mason W. // Bell. Techn. J., 1950, vo1. 29, p. 161.

4. Nye J. Physical Properties of Crystals. Moscow, Mir, 1967 (in Russian).

5. Sonin A.S., Vasilevskaya A.S. Electrooptical Crystals. Moscow, Atomizdat, 1971 (in Russian).

6. Mason W. Piezooptical Crystals and their Application in Acoustics. Moscow, Izd. inostran. liter., 1952 (in Russian).

7. Koptsyk V.A. Shubnikov's Groups. Moscow, Izd. MGU, 1966 (in Russian).

8. Mytsyk B.G., Pryriz Ya.V., Andrushchak A.S. The lithium niobate piezooptical features. // Cryst. Res. Technol., 1991, vol. 26, No. 7, p. 931-940.

\title{
Перехресний п'єзо-електрооптичний ефект на прикладі кристалів танталату літію
}

\author{
А.С.Андрущак, І.В.Сидорик, М.В.Кайдан, Р.О.Влох \\ Інститут фізичної оптики, \\ 79005 Львів, вул.Драгоманова 23 \\ Отримано 16 лютого 2000 р., в остаточному вигляді - \\ 26 вересня 2000 p.
}

У даній роботі було здійснено термодинамічний і феноменологічний описи перехресного п'єзо-електрооптичного ефекту в кристалах. Для прикладу були проведені необхідні експериментальні вимірювання вказаного ефекту в кристалах танталату літію. Для цих кристалів на основі двох різних методів вимірювання вперше було визначено різницю абсолютних коефіцієнтів перехресного п'єзо-електрооптичного ефекту $P_{33113}-P_{11113}=-4,6 \cdot 10^{-19} \mathrm{M}^{3} / \mathrm{H} \cdot \mathrm{B}$.

Ключові слова: термодинамічний та феноменологічний описи, перехресний п'єзо-електрооптичний ефект, кристал танталату літію, індуковане двозаломлення

PACS: $77.84 . \mathrm{Dc}, 78.20 . \mathrm{Hp}, 78.20 . \mathrm{Fm}$ 